\title{
Application of Remote Sensing Technology in Ecological Engineering-A Case Study of Phase I Tao River Water Diversion Project
}

\author{
Jiao Xiao Cheng ${ }^{1, a}$ \\ ${ }^{1}$ Gansu Administration of Tao River Water Diversion Project, Lanzhou, Gansu, 730000
}

\begin{abstract}
This paper aims to explore the implementation of the ecological restoration and water and soil loss control measures proposed in engineering design \& research, environmental impact assessment report and approval document with respect to the construction and environmental management of a project case, and to put forward the remedial measures and suggestions for the existing problems. The application of remote sensing technology to the eco-environment monitoring in the pre-construction phase, construction phase and operation phase of Phase I Tao River Water Diversion Project was studied. It was obtained that all disturbed areas of this project already reached the levels before the construction by combining biological control measures and vegetation measures. The ecosystem structure, processes and functions in the project construction area did not exert any great impact. The ecological environment in the project area was fragile with poor quality, and could be easily deteriorated due to the disturbance of human activities. The changes in the area and pattern of ecosystem in the project area were influenced by this project to a very small extent. The quality of natural ecological environment before the construction was basically recovered through its ecological restoration measures, and the current ecological restoration benefit was favorable. Therefore, the remote sensing technology is capable of technically demonstrating whether a project meets the acceptance conditions for environmental protection upon completion and providing basis for the follow-up application of remote sensing technology in eco-environmental investigation.
\end{abstract}

Classification No.: S156.4 Literature Code: A

\section{Introduction}

Based on the Tao diversion project is a livelihood project to solve the arid area of central Gansu and realize the sustainable development of the ecological environment of the Tao River, the application of remote sensing technology in the Tao diversion project is very necessary. The central region of Gansu Province is featured by harsh natural conditions, fragile ecological environment and shortage of water resources, which have seriously restricted the sustainable local economic and social development. Jiudianxia hydro-junction project taken as the water source, Gansu Tao River Water Diversion Project focuses on solving domestic and industrial water, rural human and animal drinking water and water of ecological environment in six key cities, counties and towns enjoying national poverty alleviation policies in central region of Gansu Province, including Dingxi and Longxi, appropriately developing local water-saving irrigation agriculture, improving domestic water and industrial and agricultural production conditions, and providing water resource guarantee for the regional economic and social development and construction of a moderately prosperous society. ${ }^{[1]}$ In recent years, many countries have started applying the remote sensing technology in environmental detection and protection, and energetically explored the functions of this technology in environment monitoring. With the ever-increasing international research level of remote sensing technology, the accuracy of satellite remote sensing monitoring has been higher and higher, and the spectral waveband has realized great-leap-forward development from early-stage visible light and infrared ray into microwave, gradually developing towards quantitative and business-oriented directions ${ }^{[2]}$. By studying the water environment monitoring based on 3D fluorescence technology, Ai Z M ${ }^{[3]}$ obtained the monitoring error of this monitoring method was lower than that of traditional methods. Chensky D A ${ }^{[4-5]}$ discussed about using two-body subminiature unmanned ships to study the environment of lake, river and different offshore areas. The error of coordinate determination was within $2 \mathrm{~m}$. The planned route was almost overlapped with the actual route, with the precision exceeding $3 \mathrm{~m}$. Wang L Y ${ }^{[6]}$ also started applying the satellite remote sensing technology in urban ecological environment monitoring, analyzed the remote sensing monitoring

aEmail: 511543286@qq.com 
of main urban water bodies in the field of environmental protection, expounded the principles and methods and satellite data extraction during the water body monitoring via the remote sensing technology, so as to reach the goal of real-time environment monitoring. Zhang B Z ${ }^{[7]}$ put forward environment monitoring via environmental remote sensing monitoring system REMS, and stated that the REMS system could realize the effective monitoring and high-precision evaluation of water color pollution. Zhao P Z ${ }^{[9]}$ conducted the data modeling and analysis using the data visualization. This method could be used to rapidly master the actual status of water body and effectively treat it, which could not only greatly improve the working efficiency but also provide a more innovative solution to the present water environmental treatment. Jiang $Z^{[10]}$ proposed environment monitoring through artificial intelligence, because it is not enough to conduct environmental protection only by relying upon manpower, but instead, new technologies and new equipment and instruments should be used. Qi X ${ }^{[11]}$ stated that biotechnology had unique superiority and development impetus in water environment monitoring and could rapidly, reasonably and effectively evaluate and analyze the water environment in environment monitoring, thus obtaining correct results. Zhang $Q^{[12]}$ focused on studying the application of remote sensing technology in water environment monitoring. Chen R [13] implemented a technical analysis of the specific applications of ion chromatography by combining its features and strengths, in an effort to enhance the concrete effect in water environment monitoring and improve the development level of environmental protection cause. Cao $\mathrm{Y}^{[14]}$ introduced the common biological monitoring methods, and studied and discussed about the specific application of biotechnology in water environment monitoring. When applying the wireless sensor network technology in autonomous water environment monitoring, Chen $\mathrm{J}^{[15]}$ put forward the beamforming long-distance transmission optimization method based on the improved Gaussian differential skeleton evolution, which could effectively mitigate the disturbance from the other receiving directions, providing effective theoretical and technical support for the long-distance transmission in water environment monitoring. Shen $M{ }^{[16]}$ implemented water environment monitoring using remote sensing technology, discussed about two different remote sensing monitoring patterns of water environment in the river basin, constructed a monitoring model with long timing sequence, laid particular emphasis on exploring the remote sensing monitoring model with long timing sequence for rivers in plateau and cold upland, making efforts to provide important information support for water environment monitoring and water resource management under the background of global changes.

Phase I Tao River Water Diversion Project belongs a non-pollution type project. According to related code requirements of the State Environmental Protection Administration, the terrestrial ecological data before and after the project construction were acquired and compared through the remote sensing investigation method, satellite remote sensing technology and GPS positioning. The vegetation changes, animal and plant varieties, protection level, distribution and animal living habits in the affected area were investigated. Next, the ecological impacts of project land occupancy and ecological restoration status of occupied land were analyzed. After the completion, Tao River Water Diversion Project can solve the urban and rural domestic water problems in the central region of Gansu, so the project construction is of very great importance. Therefore, the remote sensing technology should be applied to this project and better serve the environment monitoring and protection work in this project, thus providing an important method and basis for the environment monitoring upon the project completion.

\section{Profile of the Study Area}

Located in the central region of Gansu, Phase I Tao River Water Diversion Project belongs to the geomorphic unit of Longxi Loess Plateau, mainly consisting of tertiary stratum and quaternary deposits. The project area is distributed with major dislocation at the north edge of West Qinling, Xinglong Mountain-Maxian Mountain fault zone and regional fracture that has been active since the Quaternary system, along with four primary tributaries systems - Tao River, Weihe River, Zuli River and Wanchuan River - of the Yellow River. The main soil types include Heilu soil, sierozem, loessal soil and red clay, and this area accommodates over 300 wildlife species. Arid agricultural ecosystem and Loess Plateau steppe and desert steppe ecosystem are the two most representative ecosystems in the study area. The annual average erosion modulus in the intake area is within $3000-800 \mathrm{t} / \mathrm{km}^{2}$.a, belonging to moderate-severe erosion ${ }^{[17]}$. The scope of this remote sensing investigation and evaluation was as follows: 2 $\mathrm{km}$ at two sides of trunk stream, main canal, branch canal and water supply line, with a total area of $854.84 \mathrm{~km}^{2}$; outward $5 \mathrm{~km}$ range of main construction site and slag dump, with a total area of $1557.18 \mathrm{~km}^{2}$; outward $5 \mathrm{~km}$ range of Huining, Anding, Longxi, Yuzhong and Lintao counties, with a total area of $3830.46 \mathrm{~km}^{2}$. After the overlapped area was deducted, the scope of ecological remote sensing investigation for the final acceptance of Phase I Tao River Water Diversion Project was $4440.03 \mathrm{~km}^{2}$.

\section{Remote Sensing Data Sources and Image Processing}

\subsection{Selection of remote sensing data sources}

In the remote sensing process, the land cover data were acquired through multisource (Landsat5TM, Landsat80L1, ZY-03C, GF-1 and MODIS13 NDVI) remote sensing data with the average cloudage of single-scene image being smaller than 10 . The biological abundance index was acquired by calculating the land vegetation coverage based on MODIS NDVI data. The pollutant discharge data were obtained through Gansu Environmental 
Statistical Bulletin (2011-2018). The river length in basic geographic data was used as the water resource quantity data, and the lake and reservoir areas were expressed by the remote sensing interpretation data. The project result of Remote Sensing Investigation and Evaluation was quoted to obtain the land stress data. The normalization index derived from China National Environmental Monitoring Center ${ }^{[18]}$. The GF image data in the evaluation area in 2017 were selected, and the 2.0 m-resolution true-color data were generated by the correction and fusion of panchromatic 2.0 $\mathrm{m}$ and multispectral $8 \mathrm{~m}$ images. In key areas like slag dump and construction site, GF image data in the evaluation area in 2017 and 2018 were chosen, and $0.5 \mathrm{~m}$ true-color data were generated by the correction and fusion of panchromatic $0.5 \mathrm{~m}$ and multispectral $2 \mathrm{~m}$ images ${ }^{[19]}$.

\subsection{Processing of remote sensing images}

The manual visual interpretation method was used to interpret the investigation data via remote sensing. The waveband synthesis scheme was selected according to the surface feature spectral features of ecological environmental factors such as vegetation type, present land use status, soil erosion type and intensity. The wavebands 3,2 and 1 were chosen to synthesize true-color images by combing near-infrared, green and blue colors. According to the guideline for ecological impact assessment, the remote sensing interpretation was carried out for the current ecological damage status, land use structure, vegetation type and present water and soil loss within the scope of ecological investigation. The main geographic factors such as cultivated land, forest land, steppe, industrial and mining warehouse land, land for transportation, land for water area and water conservancy facilities and other land types were digitalized to form a foundation drawing of remote sensing interpretation. According to the field investigation and GF-2 high-resolution images, topographic map of project area and vegetation quadrat survey results, the interpretation marks of soil erosion (slope and length), land use and vegetation type were established, and the interpretation work was completed ${ }^{[20-21]}$.

\section{Investigation Conclusions}

\subsection{Investigation conclusions on the current regional ecosystem status}

From the ecosystem composition, the steppe distribution area was the largest in the natural ecosystem within the survey area of Phase I Tao River Water Diversion Project, followed by forest land, reservoir (river) water surface, pit-pond water surface and inland mudflat in succession.

The remote sensing survey results of vegetations showed that the Phase I Tao River Water Diversion Project area was located in a densely populated agricultural area with great human disturbance, and the original typical characteristics of natural vegetations were rarely seen, mainly being steppe and cultivated land at present. As for the biotic community division, forest steppe landscape played a dominant role in this area. With relatively single vegetation types, the biodiversity in this area was at a low level, the vegetation coverage was about $70 \%$, so the native eco-environmental quality was favorable. The construction camps and slag dump mainly occupied cultivated land and desert steppe, which pressed and destructed the local herbaceous vegetations. However, according to the acceptance check, all disturbed areas during the construction period already basically reached the levels before the construction through natural restoration in combination with biological measures and vegetation measures (the attached are the typical maps of 9\# tunnel export of main canal in pre-construction phase, construction phase and operation phase of this project).

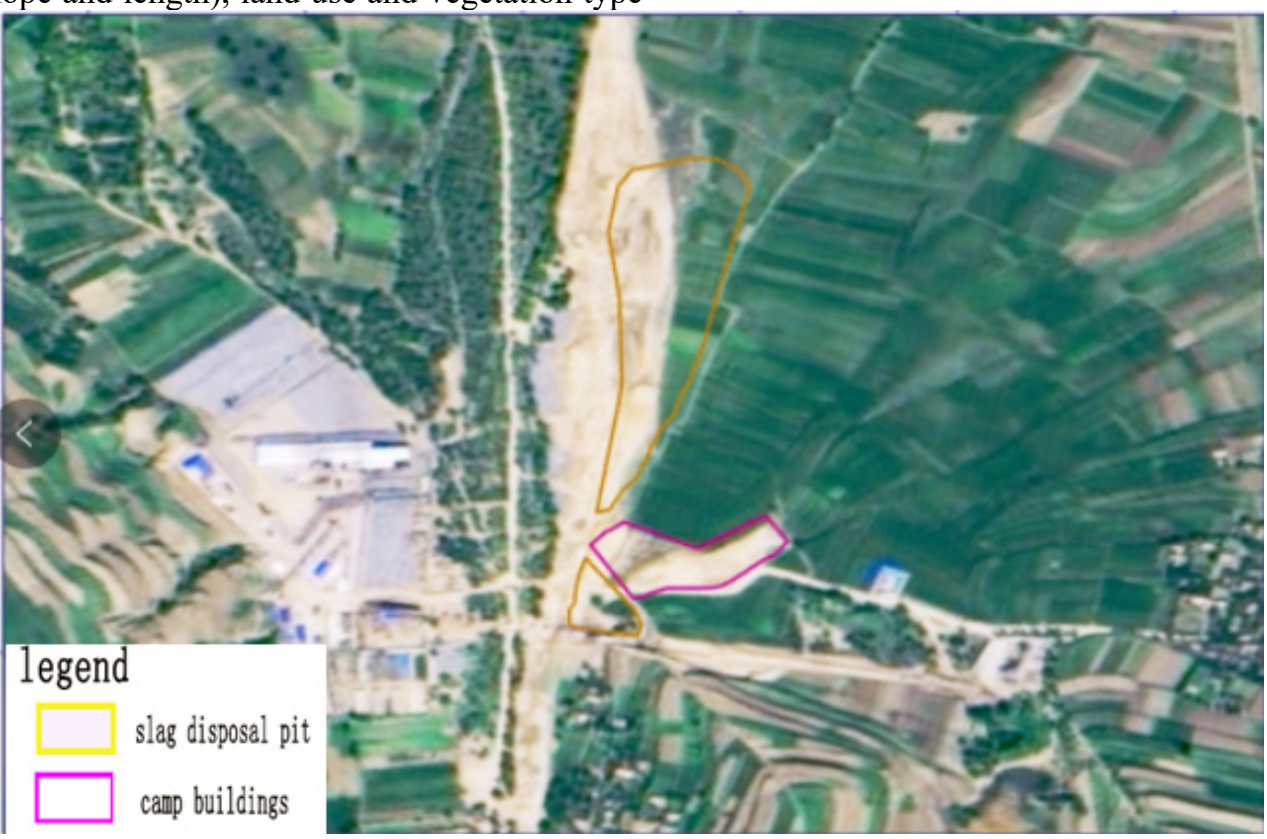

Slag dump and construction site at 10\# tunnel entrance of main canal (image in 2009)

Figure 1: Slag Dump of 9\# Tunnel Export of Main Canal in Phase I Tao River Water Diversion Project (Pre-Construction Phase) 


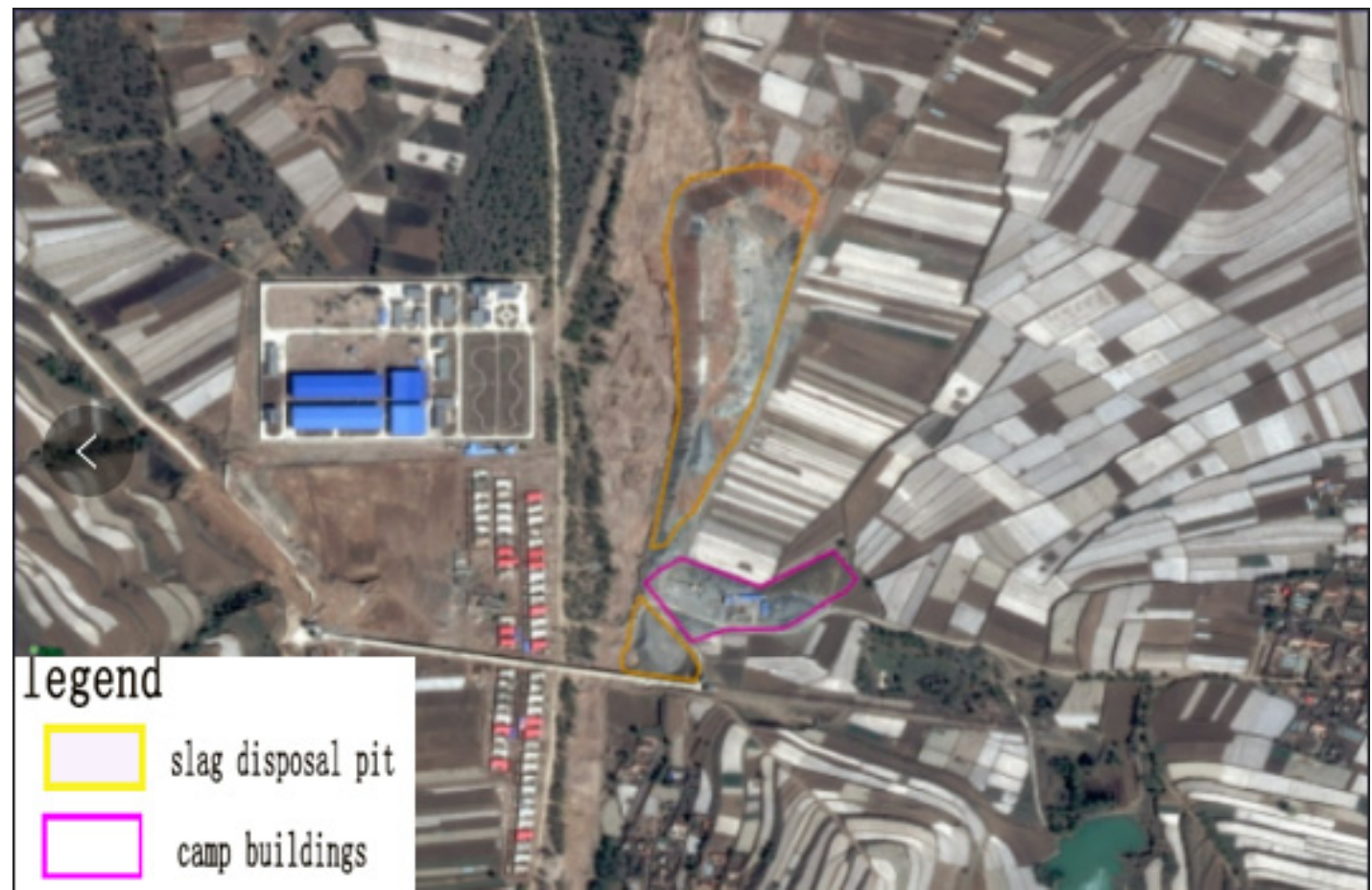

Slag dump and construction site at 10\# tunnel entrance of main canal (image in 2014)

Figure 2: Slag Dump of 9\# Tunnel Export of Main Canal in Phase I Tao River Water Diversion Project (Construction Phase)

According to the remote sensing survey results, the mild erosion dominated in the project area, and the distribution area accounted for $63.96 \%$ of total area; the distribution area of intense erosion and moderate erosion accounted for
$27.88 \%$ and $6.76 \%$, respectively. The moderate erosion occupied a small area, so was the micro-erosion $(1.40 \%)$.

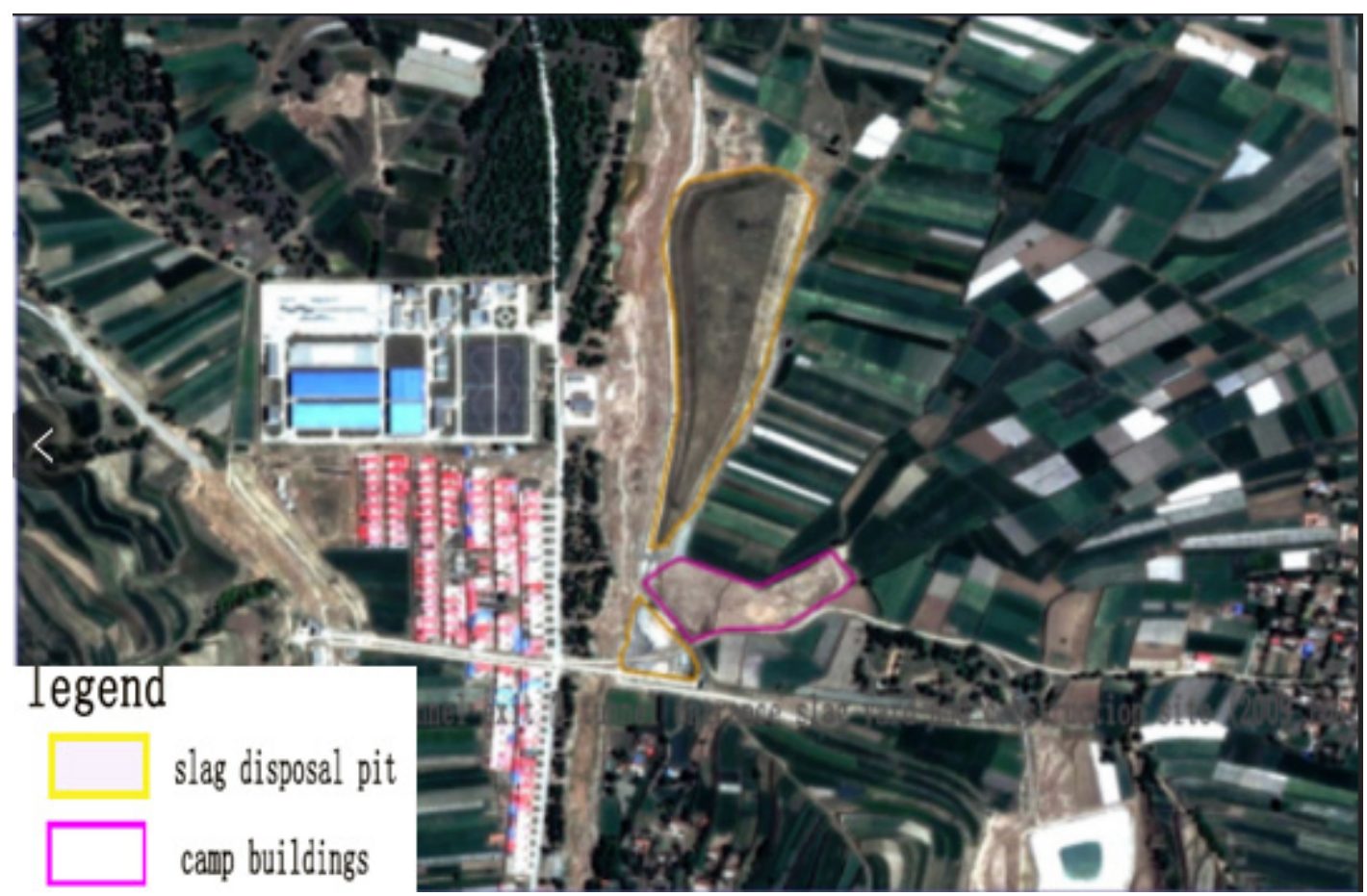

Slag dump and construction site at 10\# tunnel entrance of main canal (image in 2018)

Figure 3: Slag Dump of 9\# Tunnel Export of Main Canal in Phase I Tao River Water Diversion Project (Operation Phase)

The service function of water and soil conservancy within this project area was maintained at generally important and important levels, with the distribution areas of $2081.31 \mathrm{~km}^{2}(46.88 \%)$ and $2232.18 \mathrm{~km}^{2}$
$(50.27 \%)$, respectively. The distribution area of extremely important area was very small, only being $126.42 \mathrm{~km}^{2}(2.85 \%)$. 


\subsection{Investigation conclusions of current eco-environmental status in the study area}

Topography and landform: The project area had steep terrain and the landform was mainly erosion and denudation mountain.

Ecosystem type: The main ecosystem types in the project area mainly included agricultural ecosystem and steppe ecosystem.

Current land use status: The total area was about $4440.03 \mathrm{~km}^{2}$ in the project area, and the areas occupied by forest land, cultivated land, steppe, industrial and mining warehouse land, land for transportation, land for water area and water conservancy facilities, residential land and other land types were $796.25 \mathrm{~km}^{2}, 1015.4 \mathrm{~km}^{2}$, $2285.34 \mathrm{~km}^{2}, 4.51 \mathrm{~km}^{2}, 21.38 \mathrm{~km}^{2}, 54.51 \mathrm{~km}^{2}, 231.38$ $\mathrm{km}^{2}$ and $21.25 \mathrm{~km}^{2}$, respectively, accounting for $17.93 \%$, $22.87 \%, \quad 0.1 \%, \quad 0.48 \%, \quad 1.23 \%, \quad 5.21 \%$ and $0.48 \%$, respectively. In the study area, the main land use types were cultivated land and steppe.

Current vegetation status: The areas of arbor-shrub forest, steppe vegetation, agricultural vegetation and vegetation-free section were $769.01 \mathrm{~km}^{2}, 1140.77 \mathrm{~km}^{2}$, $2211.76 \mathrm{~km}^{2}$ and $265.08 \mathrm{~km}^{2}$, respectively, account for $17.32 \%, 25.69 \%, 49.81 \%$ and $5.99 \%$, respectively, in the total area. The main vegetation type in the evaluation area was desert vegetation, followed by crops and desert brushwood successively.

Landscape structure: The landscape types in the evaluation area included forest land, agricultural land, bare land, water resources and artificial landscape, which occupied areas of $1826.42 \mathrm{~km}^{2}, 2285.34 \mathrm{~km}^{2}, 25.89 \mathrm{~km}^{2}$ and $54.51 \mathrm{~km}^{2}$, respectively, accounting for $41.14 \%$, $51.47 \%, 0.58 \%$ and $1.22 \%$, respectively. The steppe landscape accounted for the largest proportion in the study area, with the largest quantity of patches, relatively obvious degree of dominance, high stability of landscape ecosystem and high stable level of background of natural system.

Ecosystem integrity: From the ecosystem level, the project construction would not generate any great impact on the ecosystem structure, processes or functions in the whole study area.

Current soil erosion status: The distribution areas of micro-erosion, mild erosion, moderate erosion and intense erosion were $62.2 \mathrm{~km}^{2}, 2839.87 \mathrm{~km}^{2}, 300.26 \mathrm{~km}^{2}$ and $1237.7 \mathrm{~km}^{2}$, respectively, accounting for $1.4 \%$, $63.96 \%, 6.76 \%$ and $27.88 \%$, respectively. The moderate erosion was a dominated erosion type in the project area.

\subsection{Investigation conclusions of regional eco-environmental status and variation trends}

Multi-source (Landsat5TM, Landsat80L1, ZY-03C, GF-1 and MODIS13 NDVI) remote sensing data with the average cloudage of single-scene images being smaller than 10 during May-October within 2011-2018 were taken as the investigation data sources. Five subindexes - regional biological abundance index, vegetation coverage index, water network density index, land stress index and pollution load index - and one environmental restriction index, which were involved in Phase I Tao River Water Diversion Project were interpreted and comprehensively calculated through the remote sensing technology. The investigation conclusions showed that the eco-environmental status in Anding District and Huining County within the project area was at two levels: "poor" and "general", presenting a transformation trend from "poor" into "general". The eco-environmental status in Yuzhong County, Weiyuan County and Longxi County was at "general" level. During 2011-2015, the regional eco-environmental status turned better steadily and fluctuated within 2015-2018. In general, the ecological environment in the project area was fragile with poor quality, and moreover, it was susceptible to the disturbance of human activities (attached map).

\subsection{Investigation conclusions of regional ecosystem distribution and layout and their variation trend}

The remote sensing images in the project area in 2005, 2010 and 2015 were taken as the basic data in this investigation. The remote sensing image data were Landsat8 data with resolution of $30 \mathrm{~m}$. The remote sensing technology was combined with geographic information system (GIS) technology to quantitatively analyze the temporal-spatial characteristics and driving factors of ecosystem composition in the project construction area from multiple angles: quantity, structure, dynamic degree model, pattern index, etc. According to the remote sensing investigation results, the area change of each ecosystem was the greatest, what experienced the most drastic changes were wetland ecosystem and artificial ecosystem, and their area presented an overall declining trend. The artificial surface area and other land areas changed to a moderate degree. Different ecosystems were mutually transformed frequently in a large scale before and after the construction of Phase I Tao River Water Diversion Project. Therefore, the changes in the area and pattern of one ecosystem type were influenced by this project to a very small extent.

\subsection{Investigation conclusions of ecological restoration measures and restoration effect in the project disturbed areas}

Based on a survey on the ecological restoration measures taken in the disturbed areas and slag dump of Phase I Tao River Water Diversion Project, the grass planting measure was taken in all areas disturbed by the project construction, and they had already restored the natural ecosystems in harmony with the surrounding ecological landscapes. In the slag dump of main canal, mortar laid stone slag retaining wall + slope protection via vegetation + artificial afforestation measure was taken, the ecological restoration and control rate reached over $98 \%$, satisfying the approval conditions of environmental impact assessment and completion acceptance indexes of environmental protection. By an analysis from two 
dimensions - region and survey area, the ecological restoration measures and current ecological restoration benefit of Phase I Tao River Water Diversion Project basically achieved the natural eco-environmental quality before the construction.

\section{Conclusion}

As the largest water diversion project in Gansu Province since the founding of new China, Tao River Water Diversion Project undertakes domestic and industrial water, rural human and animal drinking water and water of ecological environment in the benefited areas and provides water resource guarantee for the regional economic and social development and construction of a moderately prosperous society. The project construction was started in 2006 and completed in 2015, the water diversion was then enabled, the ecological restoration \& control was completed in over $98 \%$ of the disturbed areas through the ecological restoration and control of slag dump, stock ground and construction site, and the ecological benefit was manifested year by year. Through the remote sensing interpretation from two dimensions-region and project area, both eco-environmental status and ecological service function experienced major changes before and after the project construction. Therefore, the ecological governance, restoration measures and restoration effect of Phase I Tao River Water Diversion Project meet the completion acceptance requirements for environmental protection. According to the ecological remote sensing monitoring of the ecological changes in the beneficiary area of Tao during the pre-construction, construction and operation periods, data analysis will be carried out. In the future, if conditions are available, ecological remote sensing will continue to be monitored, and the changes before and after the changes will be compared, and remote sensing technology will be further applied to the Tao diversion project. It will better serve the environmental monitoring and protection of the Taoist Water Diversion Project, and provide important methods and basis for future environmental monitoring of the completion of the project.

\section{reference documentation}

1. Reply of Preliminary Design Report of Yintao Water Supply Project of Gansu Province (Ministry of Water Resources, Water Manager (2007) No. 36, January 1, 2007);

2. Wang $\mathrm{Xu}, \mathrm{Xu}$ Yonghua, Li Li. Application of Remote Sensing Technology in the Environmental Science and its Development Trend [ J]. Underground water, 2007 (3);

3. Ai Zhimin. Research on Water Environment Monitoring Method Based on 3 D Fluorescence Technology [ J].Low Carbon World, 2021, 11 (03): $22-23$

4. Chensky D A,Aisuev B B,Chensky A G,Fedotov A P,Poletaev A S. Water environment monitoring with an autonomous unmanned surface vessel[J]. Journal of Physics: Conference Series,2021,1728(1).

5. Myszograj Martyna. Microplastic in Food and Drinking Water - Environmental Monitoring Data[J]. Civil and Environmental Engineering Reports, 2020,30(4).

6. Wang Lianyou, Lin Jiantao, Yuan Weijian. Research on the Urban Water Environment Monitoring Method Based on Remote Sensing [ J].Surveying and GIS, 2020, 43 (11): 152 - 155

7. Zhang Baozhen. REMS Construction of Environmental Remote Sensing Monitoring Platform and its Application in Water Environment Monitoring [ J].Cleaning the World, 2020, 36 (09): $97-98$

8. Shan Li,Guang-Feng Zhang,Yuan Gao. A novel on water environment monitoring method based on millimeter wave radiometric characteristics[J]. Microwave and Optical Technology Letters, 2020,62(9).

9. Zhao Pengze, Shen Wei, Huang Shaojie, Ren Yubin, Wang Mengke. Design and Implementation of Intelligent Water Environment Monitoring Platform $[\mathrm{J}]$. Software Engineering and Applications, 2020,09(01).

10. Jiang Zhe. The Application of Artificial Intelligence in Environmental Monitoring [ J].Energy Conservation and Environmental Protection, 2020 (Z1): 99 - 100

11. Qi Xin. The Application of Biotechnology in Water Environment Monitoring [ J].Technology and Innovation, 2019 (24): 158: 159

12. Zhang Qing, Yu Xiaozhang, Li Yanhong, Liang Meina, Huang Lili, Liang Yue, Huang Liangliang. Application of Remote Sensing Technology in Water Environment Monitoring [ J].Information recording materials, 2019, 20 (10): 125 - 127

13. Chen Ran, Huang Yabin, Yu Xuebin. The Application of Ion Chromatography in Water Environment Monitoring [ J].Rural Staff, 2019 (10): 213

14. Cao Ying. The Application of Biotechnology in Water Environment Monitoring [ J].Chinese and foreign entrepreneurs, 2019 (10): 148

15. Chen Jie, Bao Xueyuan Cai, Tu Zhenyu. Optimization Method for Collaborative Beamforming of Wireless Sensing Network for Water Environment Monitoring [ J].Water Resources and Hydropower Technology, 2018, 49 (06): 118 125

16. Shen. Research on Remote Sensing Monitoring Model of River Basin Water Environment [ D].University of the Chinese Academy of Sciences (Institute of Remote Sensing and Digital Earth), 2018

17. Environmental Impact Review Report of TaoJiudianxia Water Conservancy Project and Yintao Water Supply Project, Gansu Province 
(Environmental Quality Evaluation and Research Center of Lanzhou University, No. 8, 2004);

18. Reply on the Phase I Project of Taohe Jiudianxia Water Supply Project in Gansu Province (Ganhuan spontaneous [ 2004] No. 52, November 20, 2004);

19. Report on Water and Water Conservation Plan of Gansu Yintao Irrigation Project (Tianshui Water and Water Conservation Science Test Station of Yellow River Water Conservancy Commission, Institute of Gansu Province Water and Water Conservation
Science, 1999.4);

20. The Ecological and Environmental Protection Plan of Dingxi City (2015 - 2025) (Dingxi Municipal People's Government, May 10, 2015);

21. Remote Sensing Survey and Assessment of Ecological Environment Change in Gansu Province (2000 2010) (Environmental Protection Department of Gansu Province, Gansu Environmental Science Design and Research Institute, January 11, 2014) 